УДК 101.3

\title{
ХАОС КАК КОНЦЕПТУАЛЬНЫЙ МОДУЛЬ ПОСТНЕКЛАССИЧЕСКОЙ НАУКИ: СОЦИОГУМАНИТАРНЫЕ И ФИЛОСОФСКИЕ АСПЕКТЫ
}

\author{
(C) 2013 г. М. В. Максимова
}

\section{Южно-Российский государственный технический университет (НПИ)}

Статья посвящена изучению феномена «Хаос» в современном сочиогуманитарном пространстве, в частности, выявлению его значения для формирования кониептуальной парадигмы постнеклассической научной рациональности. Автором анализируются онтологические и философские характеристики хаоса, и связанные с ним дескриптивные категории современной науки (неопределенность, хаосомность, индетерминизм, самоорганизация и т. д.). Данные категории демонстрируют высокий потенциал в проиессе формирования единой эпистемологической методологии сочиогуманитарного знания, и открывают обширные перспективы для их философского осмысления.

Ключевые слова: Хаос; хаосомность; методология; онтология; синергетика.

The article devoted to the phenomenon of "Chaos» in the contemporary socio-humanitarian space and to the identification of its implications for the development of a postnonclassical scientific rationality conceptual paradigm. Author analyzes the ontological and philosophical characteristics of chaos, and descriptive categories of modern science (chaosity, indeterminacy, selforganization, etc.). These categories demonstrate the high potential for unified epistemological socio-humanitarian knowledge methodology formation processes and give the wide prospects for the future philosophic reflection.

Key words: chaos; chaosity; methodology; ontology; synergetics.

Философский анализ современного когнитивного поля приводит к появлению множества вопросов, особенно актуальных для сознания традиционных методологических форм. Вкупе с фундаментальной, математически безупречной пассивностью классических принципов науки все активнее проявляет себя понятие, которое долгое время рассматривалось как пассивно-антагонистичное самой идее развития научного знания. Это понятие «Хаос». Сегодня же Хаос демонстрирует уникальный креационисткий потенциал, выступая вместилищем как действительных онтологических структур, так и их возможных состояний. Постнеклассическая наука поддерживает постоянную связь с Хаосом, или, как отмечает Л. Маркова, «как бы выбирает из хаоса для актуализации те или иные формы» [6]. Эти формы порождают ситуацию принципиальной неопределенно- сти, которая затрагивает все уровни бытия, пространственно-временные отношения, в которые вовлечены субъекты познания.

Осмысление происходящих трансформаций, связано, безусловно, с формированием парадигмально-инновационного мировоззрения, имеющего в своей основе «выход на поверхность» Хаоса в его онтологических, метафизических и общекультурных воплощениях. В лексикон современного ученого прочно вошел целый ряд дескриптивных гносеологических категорий, характеризующих концептуальную роль Хаоса. Хаос предстает как универсальный когнитивный модуль, что отражается в понятиях хаосомности, фрактальности, экспрессии, деструкции, и т. д. Хаос демонстрирует необычайную силу разрушительную, но и в значительно большей степени созидающую.

С философской точки зрения наиболее 
интересен вопрос о причинах возникновения сложившейся ситуации в современной науке - когда периферийная категория за достаточно короткий срок становится основополагающей для всех действующих закономерностей конкретной научной системы.

Несомненно, интерес к проблеме Хаоса имеет корни в активном развитии синергетики. Можно с уверенностью сказать, что появление синергетики произвело своеобразную научную революцию в вопросе изучения Хаоса как концептуального модуля. Резкое перемещение понятия «хаос» с периферии в эпицентр исследований связано с целым шквалом феноменальных результатов в области естественных наук, в свете которых ученые обрели надежду пролить свет на тщательно скрываемые природой закономерности развития хаотических систем. Хаотические системы впервые стали пониматься как управляемые: оказалось, что они очень чувствительны к внешним воздействиям, и динамика таких систем может быть направлена в русло желаемого движения в моменты критического состояния системы (точка бифуркации). Хаос в такой системе выступает в качестве изначального генетического принципа, который состоит в самопроизвольном процессе упорядочивания компонентов. По мере нарастания энтропии в ходе развития системы происходит возвращение к хаотическому началу, что является не разрушением, как это может показаться на первый взгляд, a ее самообновлением, переходом на новый, более высокий уровень развития. В этот момент можно практически воочию наблюдать процесс структурной гармонизации (или, как пишет В. П. Бранский, иерархизации [7]) посредством внутренних резервов самой системы, то есть на уровне самоорганизации. Таким образом, произошедший первоначальный переход к хаосу имеет однозначный конструктивный характер. Как правомерно отмечается Е. Н. Князевой, хаос проявляется как средство усложнения организации и как средство гармонизации темпов развития различных фрагментов внутри единой сложной структуры [2]. Таким образом, именно принцип хаосомности лежит в основе развития систем высокой степени сложности, представляя собой необходимое условие перехода из одного состояния в другое. Этот переход возможен исключительно через распад предыдущего состояния системы, увеличения числа степеней ее свободы и естественного самоупорядочивания ее компонентов, то есть появление порядка.

Уникальным кажется то, что именно хаос берет на себя функцию регулятора эволюции: отдельные исследователи полагают, что это противоречит этимологии данного слова [5]. Возможно, с естественнонаучной точки зрения понятие «нелинейная динамика» может быть более предпочтительным в силу определенной локализованности своего содержания, когда обязывающая к метатеоретическому осмыслению «многослойность» понятия сводится к прикладным аспектам теории динамического хаоса. С семантической же точки зрения можно заявить о том, что использование именно термина «хаос» является конструктивным при анализе когнитивных оснований современной науки, так как включает в себя философскую коннотацию, акцентирующую внимание на многообразном творческом потенциале понятия, опираясь, вместе с тем, и на результаты современных прикладных исследований.

Потенциал использования понятия «Хаос» с точки зрения его концептуальномодульных атрибутов также хорошо заметен в историко-философском ракурсе. Учитывая полидисцилинарный характер Хаоса, проникающего в самые разнообразные сферы человеческой культуры, исследование его онтологических основ принадлежит к основным направлениям философского дискурса в целом. Уже на первоначальных этапах исследования наглядно выражен концептуальный характер «хаоса», что означает наличие автореферентности как способности полагать себя и свой объект [1]. Хаос как концепт, обладающий подвижными границами и функцией смыслового генезиса, отчетливо выражен в сознании человека античности, что зафиксированное в работах такого выдающегося российского ученого, как А. Ф. Лосев [3]. Он указывает на связанность первоначала с хаотической бесформенностью, которая порождает впоследствии форму, объект, универсум. Такая особенность античного сознания задала мировоззренческий вектор на ближайшие несколько столетий: как отмечает Н. А. Хренов, «потому древний грек и обладал столь пора- 
зительной пластикой, в которой утверждается его чувство формы, что в своем сознании он постоянно имел образ хаоса» [8].

Очевидно, масштаб «популярности» идеи Хаоса как формообразующей онтологический основы универсума в античности может быть сравним только с современной научной картиной мира: в 70-е годы XX века креативный потенциал Хаоса был буквально заново открыт после долгих веков забвения. Если на протяжении долгих лет аскетичного механицизма классической науки хаосу просто не было места - он исполнял роль своеобразной методологической черной дыры, от контррепродуктивних функций которой спешили побыстрей избавиться, то в начале прошлого века, наконец-то, «двуликий Янус» Овидия вновь обрел свои хорошо забытые созидательные смыслы.

По мнению С. Манна [5], новая наука о хаосе определяется следующими ключевыми принципами: теория хаоса применима исключительно в динамических системах как системах с очень большим количеством подвижных компонентов; внутри этих систем существует специфического рода закономерности, согласно котором по внешнему виду хаотичная совокупность данных может быть внезапно упорядочена; подобные «хаотические» системы показывают большую чувствительность к начальным условиям, когда небольшие изменения каких-либо начальных координат могут привести в дальнейшем к самым масштабным диспропорциям. Последнее свойство даже позволяет ученым говорить о перспективе своеобразного «управления» хаотическими системами, заключающегося в «переводе таких систем посредством слабых воздействий из режима хаотических колебаний на требуемый динамический режим (тем самым, стабилизируя их поведение)» [4]. Таким образом, современная наука позволяет раскрыть поведенческий «механизм» окружающих нас сложных систем - создаваемых, регулируемых и разрушаемых хаосом.

Общенаучный понятийный аппарат синергетики, и хаос, как один из ее основных гносеологических инструментов, зачастую вызывает вопрос о правомерности экстраполяции практических выкладок естественнонаучного знания в философской (со- циогуманитарной) сфере. На самом деле, использование в синергетике антиномии хаос-порядок, и связанных с ней концептуальных понятий (нелинейность, случайность, диссипативность и т. д.) имеет целью обоснование данных концептов как общенаучных, междисциплинарных, имеющих универсальную значимость в различных сферах современного научного знания. Также необходимо отметить, что мишень синергетического анализа - самоорганизующиеся системы, рассматриваются сквозь призму специфических особенностей (открытость, динамичность, стохастичность) и могут иметь совершенно другой смысл при отсутствии этих условий. В частности, В. П. Бранским [7] упоминается два абсолютно разных «хаоса» - хаос статический как вульгарный беспорядок, и хаос динамический как активный созидающий субстрат. Поэтому, в отношении хаоса как концептуальной креативной структуры постнеклассической научной парадигмы, так же, как и в отношении основных понятий, используемых в синергетике, можно заявить о новых формах, которые получили эти понятия в свете определенных условий, естественно заданных условиями «нелинейной» природой универсума. Синергетическая интерпретация вносит в данные понятия принципиально иной смысл, синхроничный ритмам современности, в буквально степени сообщая им общетеоретическое ускорение, и, вместе с тем, «выносит» их в качестве онтологических атрибутов в топ когнитивных философских исследований.

Как отмечает В. П. Бранский [7], синтез порядка и хаоса в социальных системах имеет два основных аспекта - это существование порядка исключительно за счет хаоса, и то, что за счет порядка система способна адекватно реагировать на внешний хаос, сохраняя свою внутреннюю устойчивость. То есть, дихотомия «порядок-хаос» не претерпевает сколько-нибудь существенных изменений в отношении социального пространства, за исключением, возможно, логичного смещения акцента на созидательный потенциал хаоса, и частую цикличность преобразования порядка в хаос, что наглядно выражается в нестабильности единого вектора социального развития. Исследователями обосновывается необходимость троичного структурирова- 
ния в отношении социальных систем, когда выделяется онтологический уровень самоорганизации (социальные институты), гносеологический (поток знаний, теоретически осмысленных концепций парадигмального характера, и т. д.), и аксиологический уровень (изменения в социальных ценностях). Такая дифференциация отражает сущность социального пространства, фиксируя его многомерность. Использование синергетики в социальной сфере позволяет подойти с нестандартных позиций к решению вопросов об оценке роли социальных кризисов в коэволюции общества с универсумом как холистической системой, включая в спектр приоритетных задач актуальность использования творческого потенциала хаоса.

Несомненно, что среди множества научных направлений, в которых синергетика успешно применяет свой инструментарий, социальная сфера является наиболее неоднозначной. Это связано со спецификой использования понятия «хаос» в изучении социальных трансформаций, а именно - в предельно высоком уровне сложности социальных систем, включающих в себя активный субъектный фактор. Тем не менее, используемые синергетикой категории сохраняют свою гносеологическую универсальность.

Междисциплинарная направленность современной постнеклассической методологии позволяет философам по-новому осмыслить потенциал хаотических структур, основываясь, при этом, на достижениях нелинейной динамики. Космос, являясь единой системой, не просто допускает хаос в своей структуре - хаос играет в ней главнейшую роль, обеспечивая хрупкий баланс между бытием и небытием, между развитием и началом распада. Е. Н. Князева [2] выделяет ряд основных функций, которые выполняет хаос в человекоразмерных системах. Среди них «хаос как фактор приспособления к изменчивым условиям окружающей среды», «переход от порядка к хаосу, от симметрии к асимметрии и обратно как способ рождения красоты», «хаотичность, разбросанность, разнообразие элементов как основа достижения их единства, организации», «хаос как стимул, толчок эволюции, спонтанность как жизненный порыв» - в этот перечень мо- жет быть также добавлена креационисткая активность хаоса, его способность создавать инновации как «творческие» когнитивные инварианты, которые стимулируют процесс эволюции системы. Приведенные характеристики хаоса, используемые в синергетике, имеют однозначный созидательный оттенок: можно сказать о том, что мера хаосомности системы побуждает ее не столько к разрушению, сколько к развитию, к самообновлению, связанному со спонтанным появлением нового.

Современная наука ориентирована на исследование феномена «Хаос» как креативного начала, создающего, в результате, упорядоченные структуры, которые окружают человека на разных уровнях бытия как в онтологическом, так и в метафизическом смысле. Постнеклассическая модель научной рациональности «снимает» с понятия «Хаос» мифологические наслоения, впервые представляя его как когнитивный метод познания. Сегодня можно с уверенностью заключить, что хаосомность является неотьемлемым свойством большинства процессов, которых мы относим к категории «самоорганизующихся» - что, по сути, означает «живых», находящихся в постоянном развитии. Перспектива дальнейшего использования концептуального модуля «Хаос» открывает обширные эпистемологические горизонты, позволяя раскрыть подлинные закономерности универсума как единой системы взаимосогласованных компонентов.

\section{Литература}

1. Делез Ж., Гваттари Ф. Что такое философия? - СПб.: Алетейя, 1998. - 228 с.

2. Князева Е. Н. Балансирование на краю хаоса как способ творческого обновления. // Синергетическая парадигма. Человек и общество в условиях нестабильности. - М.: Прогресс-Традиция, 2003. - С. 123-140.

3 . Лосев $A$. $\Phi$. История античной эстетики. Итоги тысячелетнего развития. - В 2-х кн. - М.: АСТ, 2000. - 624 с.

4. Лоскутов $A$. Нелинейная динамика, теория динамического хаоса и синергетика: перспективы и приложения. [Электронный pecypc] / Синергетика: сайт С. П. Курдюмо- 
ва. - Режим доступа: http://spkurdyumov. narod.ru/loskutov.htm, свободный (2.02.2013). - Загл. с экрана.

5. Манн $C$. Теория хаоса и стратегическое мышление. [Электронный ресурс] / Синергетика: сайт С. П. Курдюмова. - Режим доступа: http://spkurdyumov.narod.ru/mann. htm, свободный (2.02.2013). - Загл. с экрана.

6. Маркова Л. А. Философия из хаоса. -
М.: Канон, 2004. - 384 c.

7. Оганян К. М., Бранский В. П., Астафьев A. K. Социальная синергетика. - СПб.: Издательский дом «Петрополис», 2010. $192 \mathrm{c}$.

8. Хренов Н. А. Культура в эпоху социального хаоса. - М.: Едиториал УРСС, 2011. - $448 \mathrm{c}$.

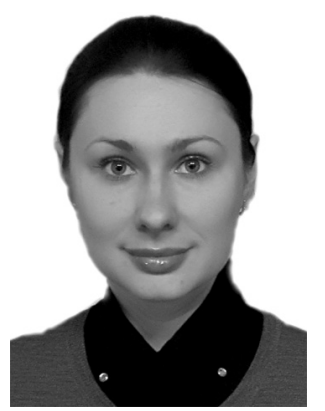

Марина Валерьевна Максимова - кандидат философских наук, старший преподаватель кафедры философии Южно-Российского государственного технического университета (НПИ).

Marina Valeriyevna Maximova - Ph.D., Candidate of Philosophy, senior lecturer at South-Russian State Technical University (NPI) Philosophy department.

346428, Ростовская обл., г. Новочеркасск, ул. Просвещения, 132 132 Prosveshcheniya st., 346428, Novocherkassk, Rostov reg., Russia

Тел.: +7 (8632) 25-54-27; e-mail: aspera-86@mail.ru 